\title{
Association of serum vitamin D levels with disease severity, systemic inflammation, prior lung function loss and exacerbations in a cohort of patients with chronic obstructive pulmonary disease (COPD)
}

\author{
Ilka Jorde $^{1 \#}$, Sabine Stegemann-Koniszewski ${ }^{1 \#}$, Kristin Papra ${ }^{1}$, Sebastian Föllner $^{1}$, Anke Lux $^{2}$, \\ Jens Schreiber ${ }^{1}$, Eva Lücke ${ }^{1}$ \\ ${ }^{1}$ Department of Pneumology, University Hospital and Medical Faculty, Health Campus Immunology, Infectiology, and Inflammation, Otto-von- \\ Guericke University Magdeburg, Magdeburg, Germany; ${ }^{2}$ Institute for Biometrics and Medical Informatics, Medical Faculty, Otto-von-Guericke \\ University Magdeburg, Magdeburg, Germany \\ Contributions: (I) Conception and design: J Schreiber, E Lücke; (II) Administrative support: None; (III) Provision of study materials or patients: J \\ Schreiber, E Lücke; (IV) Collection and assembly of data: K Papra, S Föllner; (V): Data analysis and interpretation: All authors; (VI): Manuscript \\ writing: All authors; (VII): Final approval of manuscript: All authors. \\ \#These authors contributed equally to this work. \\ Correspondence to: Eva Lücke, MD. Universitätsmedizin Magdeburg, Universitätsklinik für Pneumologie, Leipziger Straße 44, 39120 Magdeburg, \\ Germany. Email: eva.luecke@med.ovgu.de.
}

Background: Vitamin D deficiency has been associated with chronic disorders including chronic obstructive pulmonary disease (COPD) but the relationships with inflammation, exacerbations and disease progression remain unclear.

Methods: In this monocentric cross-sectional observational study we analyzed the disease status, systemic inflammation, prior exacerbation frequency and loss in lung function in relation to serum 25-hydroxyvitamin D (25-OHD) levels in a cohort of 94 patients with COPD. Serum 25-OHD, C-reactive protein, interleukin-6 and tumor necrosis factor- $\alpha$ were quantified. Exacerbation frequencies and sunlight exposure were assessed. These parameters were analyzed in correlation to the current forced expiratory volume in $1 \mathrm{~s}$ $\left(\mathrm{FEV}_{1}\right)$, the individual average 3-year $\mathrm{FEV}_{1}$ decline and the Global Initiative for Chronic Obstructive Lung Disease (GOLD) stage.

Results: We observed fair correlation between serum 25-OHD and the current $\mathrm{FEV}_{1}(\mathrm{r}=0.38, \mathrm{P}<0.001)$. Furthermore, mean serum 25-OHD was significantly altered between patients of GOLD stages I-IV $(\mathrm{P}=0.013)$. There was weak negative correlation of $25-\mathrm{OHD}$ and the average annual change of the $\mathrm{FEV}_{1}$ $(\mathrm{r}=-0.26, \mathrm{P}<0.05)$. Furthermore, we observed fair negative correlation between 25-OHD and C-reactive protein $(\mathrm{r}=-0.32, \mathrm{P}<0.01)$ as well as weak negative correlation with interleukin-6 $(\mathrm{r}=-0.23, \mathrm{P}<0.05)$. While the exacerbation frequency significantly differed between GOLD stages $(\mathrm{P}=0.04)$, there was no direct association between exacerbations and 25-OHD levels.

Conclusion: Our data confirm frequent vitamin D deficiency in COPD and point out correlations between 25-OHD levels, systemic inflammation, disease severity and progression.

Keywords: Chronic obstructive pulmonary disease (COPD); inflammation; exacerbation; vitamin D; forced expiratory volume in $1 \mathrm{~s}$ decline $\left(\mathrm{FEV}_{1}\right.$ decline); 25-hydroxyvitamin $\mathrm{D}$ (25-OHD)

Submitted Nov 03, 2020. Accepted for publication Mar 18, 2021.

doi: $10.21037 /$ jtd-20-3221

View this article at: http://dx.doi.org/10.21037/jtd-20-3221 


\section{Introduction}

Chronic obstructive pulmonary disease (COPD) is a common and currently incurable, but treatable disease. It is one of the leading causes of morbidity and mortality worldwide and poses a significant social and economic burden (1). Importantly, the prevalence, morbidity and mortality attributable to COPD are predicted to increase over the coming years (2). The disease is generally characterized by usually progressive, not fully reversible airflow limitations even though there are instances where lung function parameters are nearly constant or even improving (3).

Research on the pathophysiological mechanisms underlying COPD is essential and has also focused on comorbidities $(4,5)$. In this context, there has been a growing interest in the role of vitamin $\mathrm{D}$ and several lung diseases have indeed been shown to be associated with low vitamin D [25-hydroxyvitamin D (25-OHD)] levels. As such, significant correlations have been observed for lung cancer, cystic fibrosis, bronchial asthma and also COPD (6). Predominantly noncalcemic effects of vitamin $\mathrm{D}$, such as the production of antimicrobial peptides and the regulation of inflammatory responses are believed to play a central role (7). In COPD, vitamin D deficiency has been shown to correlate with airway obstruction and the frequency of exacerbations due to respiratory infections, which display a major complication and cause for disease progression (8-11). This is in line with the observation that vitamin $\mathrm{D}$ deficiency is associated with an increased risk of respiratory infections in the general population and that vitamin D supplementation can have beneficial effects on acute respiratory infection $(9,12)$. However, while also in meta-analyses lower vitamin $\mathrm{D}$ levels have been found associated with exacerbations, vitamin D deficiency not necessarily increases the risk for exacerbations (13). Consequently, effects of high-dose vitamin D substitution on the progression of COPD were studied, however without clear results (14-16). While positive effects of supplementation on lung function and acute exacerbations in COPD have been reported in meta-analysis (16), others likewise report vitamin D not to improve lung function decline (17). Nevertheless, another recent systematic review and meta-analysis suggests vitamin $\mathrm{D}$ supplementation to reduce the rate of moderate and severe exacerbations in COPD patients with vitamin D levels below $10 \mathrm{ng} / \mathrm{mL}$ (18). Ultimately, much remains elusive regarding the role of vitamin D levels in COPD risk and progression as well as the mechanisms underlying the observed correlations $(7,19)$.

The present study aimed to increase our knowledge of the correlations between 25-OHD levels and COPD and specifically addressed the hypothesis that reduced levels of serum 25-OHD correlate with disease progression and systemic inflammation in COPD. To this end, we analyzed 25-OHD levels in relation to systemic inflammation [serum C-reactive protein (CRP), interleukin (IL)-6 and tumor necrosis factor $(\mathrm{TNF})-\alpha)$ ], exacerbation frequencies, sunlight exposure and disease progression in a cohort of COPD patients.

We present the following article in accordance with the STROBE reporting checklist (available at http://dx.doi. org/10.21037/jtd-20-3221).

\section{Methods}

\section{Ethics approval and consent to participate}

The cross-sectional observational study with retrospective longitudinal data analysis adhered to the guidelines of the Declaration of Helsinki (as revised in 2013) and was approved by the institutional ethical committee (Ethikkommission of the Otto-von-Guericke University Magdeburg; file No. 12/11). All patients gave written informed consent.

\section{Patients}

All subjects were recruited from the same geographical area in central Germany. The cohort included 94 COPD patients (64 male, 30 female) recruited from specialized centers during 2011-2012 as inpatients and outpatients, for which documented regular outpatient lung function monitoring and/or the history of documented acute exacerbations for at least the past 3 years were available. No explicit sample size calculation was performed. The sample size was reached through continuous and unbiased recruitment of all patients matching the inclusion criteria and giving informed consent over the defined period of time. Upon recruitment, $\mathrm{n}=28$ patients were treated as inpatients and $\mathrm{n}=66$ were outpatients. All subjects were Caucasian and were aged between 46 and 84 years. COPD was diagnosed according to the Global Initiative for Chronic Obstructive Lung Disease (GOLD) guidelines effective at the time of our study and patients were attributed to GOLD stages I to IV according to these guidelines (20). Specifically, according to spirometric criteria COPD was defined using the fixed ratio 
of forced expiratory volume in $1 \mathrm{~s}\left(\mathrm{FEV}_{1}\right) /$ vital capacity (VC) $<0.70$. Non-inclusion criteria were current asthma, a history of asthma or other respiratory diseases besides COPD, relevant cardiac diseases and especially cardiac insufficiency, autoimmune diseases, malignancies (except non-melanoma skin cancer), acute infections, chronic intestinal disease, severe kidney dysfunction, liver dysfunction (cirrhosis, fibrosis) and hyperparathyroidism. Further, all patients under supplementation or medication affecting the vitamin $\mathrm{D}$ or calcium metabolism were excluded.

\section{Data sampling and laboratory parameters}

All subjects were physically examined and performed a structured interview. Through a questionnaire, which was developed for this study, the number of COPD-related hospitalizations over the previous 12 months, regular sports activities (choice of none, about $2 \mathrm{~h}$, more than $4 \mathrm{~h} /$ week), the frequency of sunlight exposure (choice of little, 2 3 times/week or nearly every day) and its duration (choice of $<1,1-3$ or $>3 \mathrm{~h}$ ), past and current smoking habits (current smoking yes or no, number of cigarettes and years) and the occupational history were assessed. Patients were furthermore asked whether and how often during the previous 12 months, they experienced increased cough, sputum and/or dyspnea with and without fever leading to adjustment of therapy. From these data, the number of exacerbations (occasions of increased cough, sputum and dyspnea requiring intensified therapy) were documented for the subsequent analyses (21). We grouped patients into a high-frequency (at least two exacerbations per year) or a low-frequency (one or no exacerbation per year) exacerbation phenotype.

Blood gas analysis from arterialized blood was performed on a Radiometer ABL 520 and pulmonary function was assessed through body plethysmography and spirometry by a trained staff member. Body plethysmography and spirometry were performed at a MasterScreen PFT Pro Workstation (Viasys Healtcare, Germany). The measurements including calibration were performed according to the American Thoracic Society (ATS)/European Respiratory Society (ERS) recommendations. The European Community for Coal and Steel (EGKS)-reference values were used for the measurements with body temperature pressure saturated (BTPS)-correction. All patients were under medical monitoring for COPD by specialized pulmonologists, including regular lung function measurements every 3-6 months and documentation of acute exacerbations in an outpatient care setting. The mean annual decrease in $\mathrm{FEV}_{1}\left(\triangle \mathrm{FEV}_{1}\right)$ was calculated by the formula $\left\{\left[\left(\mathrm{FEV}_{1}\right)_{\text {year-3 }}-\left(\mathrm{FEV}_{1}\right)_{\text {year-2 }}\right]+\left[\left(\mathrm{FEV}_{1}\right)_{\text {year-2 }}-\left(\mathrm{FEV}_{1}\right)_{\text {year-1 }}\right]\right.$ $\left.+\left[\left(\mathrm{FEV}_{1}\right)_{\text {year }-1}-\left(\mathrm{FEV}_{1}\right)_{\text {current }}\right]\right\} / 3$.

Serum samples were analyzed for 25-OHD (radioimmunoassay) and CRP (latex enhanced immunoturbidimetric assay) at the Institute of Clinical Chemistry and Pathobiochemistry, University Hospital Magdeburg. Serum 25-OHD levels $<20 \mathrm{ng} / \mathrm{mL}$ indicate vitamin D deficiency and levels between 20 and $30 \mathrm{ng} / \mathrm{mL}$ are defined as insufficient, i.e., suboptimal $(22,23)$. Serum TNF- $\alpha$ (Quantikine ELISA DTA00C, R\&D Systems) and IL-6 (Quantikine ELISA D6050, R\&D Systems) were assessed at the Institute of Molecular and Clinical Immunology, University Hospital Magdeburg. Cut-offs for CRP, IL- 6 and TNF- $\alpha$ as applied in Table 1 are derived from (24).

\section{Statistical analysis}

For the statistical analysis of anonymized data, the software IBM SPSS Statistics, Version 18.0 and GraphPad Prism 7.05 and 8.0 were used. Shapiro-Wilk normality tests were performed. These revealed a non-Gaussian distribution. Therefore, non-parametric statistical tests were used for the analysis: Kruskal-Wallis test or Mann-Whitney-Utest for group comparisons, Spearman rank correlation for correlation analyzes (25). In the correlation analyzes, the strength of the correlation was interpreted as weak or no correlation, if $\mathrm{r}$ was $<0.3$, as fair for $\mathrm{r}$ between 0.3 and 0.5 , as good for $\mathrm{r}$ between 0.5 and 0.7 and as high, if $\mathrm{r}$ was $>0.7$.

In the case of significant associations, the relevant variables were included in a multiple linear regression analysis. Here, the backward selection was used.

A probability of error of $\alpha=0.05$ was assumed as the significance level for all statistical tests.

\section{Results}

\section{Baseline patient characteristics}

The study included 94 subjects which at the point of sampling showed a mean $\mathrm{FEV}_{1}$ of $1.4 \mathrm{~L}$ (SD 0.6). The current COPD severity according to GOLD was stage I in 4, stage II in 40, stage III in 22 and stage IV in 28 patients. The mean $\mathrm{FEV}_{1}(\mathrm{SD})$ was $2.4(0.5)$ in GOLD stage I, 1.6 (0.5) in GOLD stage II, 1.25 (0.35) in GOLD stage III and $0.87(0.27)$ in GOLD stage IV. Forty patients were 
Table 1 Inflammatory parameters

\begin{tabular}{|c|c|c|c|c|c|c|}
\hline Patient group & \multicolumn{2}{|c|}{ CRP (mg/L) } & \multicolumn{2}{|c|}{ IL-6 (pg/mL) } & \multicolumn{2}{|c|}{ TNF- $\alpha(p g / m L)$} \\
\hline \multicolumn{7}{|l|}{ GOLD stage } \\
\hline GOLD I & 4.9 (3.8); 3 & 67 & 6.7 (5.8); 4 & 25 & $0.4(0.5) ; 3$ & 0 \\
\hline GOLD II & 12.3 (19.2); 33 & 58 & 6.8 (9.5); 39 & 18 & 2.4 (4.9); 22 & 5 \\
\hline GOLD IV & 11.7 (11.8); 24 & 71 & 9.1 (12.0); 27 & 26 & $0.6(0.6) ; 16$ & 0 \\
\hline $\begin{array}{l}\text { P value } \\
\text { (Kruskal-Wallis test) }\end{array}$ & 0.35 (n.s.) & & 0.61 (n.s.) & & 0.17 (n.s.) & \\
\hline \multicolumn{7}{|l|}{ Exacerbation frequency } \\
\hline $\begin{array}{l}\text { High frequency } \\
\text { exacerbation } \\
\text { phenotype }\end{array}$ & 16.3 (22.4); 38 & & 10.8 (13.9); 39 & & 2.3 (4.6); 26 & \\
\hline $\begin{array}{l}\text { P value } \\
\text { (Mann-Whitney test) }\end{array}$ & 0.10 (n.s.) & & $0.016^{*}$ & & 0.68 (n.s.) & \\
\hline \multicolumn{7}{|l|}{ In- or outpatient } \\
\hline Outpatient $(n=66)$ & 7.9 (11.2); 51 & & 4.7 (6.1); 66 & & $1.7(4.0) ; 35$ & \\
\hline Inpatient $(\mathrm{n}=28)$ & 23.2 (27.8); 28 & & 15.6 (17.0); 26 & & $1.1(1.3) ; 24$ & \\
\hline $\begin{array}{l}\text { P value } \\
\text { (Mann-Whitney test) }\end{array}$ & $0.011^{*}$ & & $0.0004^{\star \star *}$ & & 0.44 (n.s.) & \\
\hline
\end{tabular}

CRP, C-reactive protein; IL, interleukin; TNF, tumor necrosis factor; SD, standard deviation; GOLD, Global Initiative for Chronic Obstructive Pulmonary Diseases; n.s., not significant. * $\mathrm{P}<0.05$; ${ }^{* *}, \mathrm{P}<0.001$.

attributed to the high-frequency exacerbation phenotype and 43 to the low-frequency exacerbation phenotype. Table 2 lists the analyzed parameters together with their category boundaries and the respective sample size. The relevant patient characteristics are summarized in Table 3.

\section{COPD progression and exacerbations}

The $\Delta \mathrm{FEV}_{1}$ significantly differed between the different GOLD stages (Kruskal-Wallis test, $\mathrm{P}=0.048$; Dunn's multiple comparisons between groups not significant) (Figure 1A). When combining patients of GOLD stages I and II into one group due to the small sample size in the GOLD stage I group, there was again a significant association of $\triangle \mathrm{FEV}_{1}$ and the GOLD stage (Kruskal-Wallis test, $\mathrm{P}=0.021$ ) with a significantly increased lung function decline in GOLD stage IV as compared to GOLD stages
I + II (Dunn's multiple comparison, $\mathrm{P}=0.039$ ) (Figure 1B). The number of exacerbations was significantly altered with respect to the GOLD stage (Kruskal-Wallis test, $\mathrm{P}=0.04$ ), with a significant difference between GOLD stages II and IV (Dunn's multiple comparison, $\mathrm{P}=0.045$ ) (Figure 1C). Patients of the high-frequency exacerbation phenotype showed significantly increased $\triangle \mathrm{FEV}_{1}$ values, indicating an accelerated increase in bronchial obstruction (MannWhitney test, $\mathrm{P}=0.015$ ) (Figure $1 D$ ).

\section{Characterization of inflammatory parameters}

In our cohort, we did not detect a significant association of systemic inflammation with the different GOLD stages (Table 1). Furthermore, the frequency of patients with heightened CRP, IL- 6 or TNF- $\alpha$ was not overtly increased in any of the GOLD stages (Table 1). In patients of the 
Table 2 Summary of study parameters

\begin{tabular}{lcc}
\hline Parameter & Minimum/maximum & Sample size $(\mathrm{n})$ \\
\hline Body weight $(\mathrm{kg})$ & $42 / 115$ & 93 \\
Body mass index $\left(\mathrm{kg} / \mathrm{m}^{2}\right)$ & $14.2 / 42.1$ & 93 \\
$\mathrm{FEV}_{1}(\mathrm{~L})$ & $0.36 / 2.82$ & 93 \\
$\Delta \mathrm{FEV}_{1}(\mathrm{~L})$ & $-0.17 / 0.53$ & 76 \\
exacerbations/previous year & $0 / 10$ & 83 \\
$25-O H D(\mathrm{ng} / \mathrm{mL})$ & $8.4 / 51.1$ & 94 \\
CRP & $0.8 / 110.7$ & 79 \\
IL-6 & $0.4 / 66.2$ & 92 \\
TNF- $\alpha$ & $0.0 / 20.6$ & 59 \\
sunlight exposure (h/week) & $1.0 / 21.0$ & 93 \\
sunlight exposure (frequency/week) & $1 / 7$ & 93 \\
\hline
\end{tabular}

$\mathrm{FEV}_{1}$, forced expiratory volume in 1 second; $\triangle \mathrm{FEV}_{1}$, mean annual decrease in $\mathrm{FEV}_{1}$ over the previous three years; $25-\mathrm{OHD}$, 25-hydroxyvitamin D; CRP, C-reactive protein; IL, interleukin; TNF, tumor necrosis factor.

Table 3 Patient characteristics (recruited $n=94$ )

\begin{tabular}{|c|c|}
\hline Characteristics & Value \\
\hline Male, n (\%) & $64(68.1)$ \\
\hline Current smoker, n (\%) & $26(27.7)$ \\
\hline \multicolumn{2}{|l|}{ GOLD stage, n (\%) } \\
\hline GOLD I & $4(4.25)$ \\
\hline GOLD ॥ & $40(42.55)$ \\
\hline GOLD III & $22(23.4)$ \\
\hline GOLD IV & $28(29.8)$ \\
\hline \multicolumn{2}{|l|}{ Exacerbation phenotype, n (\%) } \\
\hline Low-frequency & $43(51.8)$ \\
\hline High-frequency & $40(48.2)$ \\
\hline Inpatients, n (\%) & $28(29.8)$ \\
\hline Outpatients, n (\%) & $66(70.2)$ \\
\hline Age (years) $(n=94)$, mean (SD) & $68.6(9.4)$ \\
\hline Pack-years $(n=85)$, mean (SD) & $36.6(21.3)$ \\
\hline BMI $\left(k g / m^{2}\right)(n=93)$, mean (SD) & $26.8(5.4)$ \\
\hline $\mathrm{FEV}_{1}(\mathrm{~L})(\mathrm{n}=93)$, mean $(\mathrm{SD})$ & $1.35(0.56)$ \\
\hline $\mathrm{FEV}_{1}(\%)(\mathrm{n}=93)$, mean (SD) & $50.4(18.6)$ \\
\hline $\mathrm{FEV}_{1} / \mathrm{NC}(\%)(\mathrm{n}=93)$, mean (SD) & $70.2(15.5)$ \\
\hline
\end{tabular}

GOLD, Global Initiative for Chronic Obstructive Pulmonary Diseases; $\mathrm{BMI}$, body mass index; $\mathrm{FEV}_{1}$, forced expiratory volume in 1 second; VC, vital capacity. high frequency exacerbation phenotype, there was a trend for increased inflammation with respect to CRP and TNF- $\alpha$ levels and a significant increase in IL-6 (Table 1). Of note, both CRP and IL- 6 , but not TNF- $\alpha$, levels were significantly increased in the inpatient collective as compared to the outpatients (Table 1).

\section{Associations between serum 25-OHD levels and current disease severity}

Most patients $(\mathrm{n}=77 ; 82 \%)$ revealed serum 25-OHD levels below $30 \mathrm{ng} / \mathrm{mL}$ while more than half showed serum levels below $20 \mathrm{ng} / \mathrm{mL}(\mathrm{n}=51 ; 54 \%)$ (Figure $2 A)$. Furthermore, we observed a fair positive correlation between serum 25-OHD levels and the $\mathrm{FEV}_{1}$ (Spearman $\mathrm{r}=0.38, \mathrm{P}<0.001$ ) (Figure $2 B$ ) and there were significant differences in the serum 25-OHD levels between the different GOLD stages [Kruskal-Wallis test, $\mathrm{P}=0.013$; Dunn's multiple comparisons, $\mathrm{P}=0.043$ (GOLD I vs. GOLD IV)] (Figure 2C). In analysis of GOLD stages II to IV only, to exclude bias due to the small sample size in GOLD stage I, significant differences between GOLD stages persisted [Kruskal-Wallis test, $\mathrm{P}=0.04$; Dunn's multiple comparisons, $\mathrm{P}=0.034$ (GOLD II $v s$. GOLD IV)]. Patients in GOLD stages I, II, III and IV showed mean 25-OHD levels of 29.7 (SD 6.5), 22.6 (SD 8.9), 21.0 (SD 9.4) and 17.8 (SD 7.7) ng/mL. Therefore, patients 

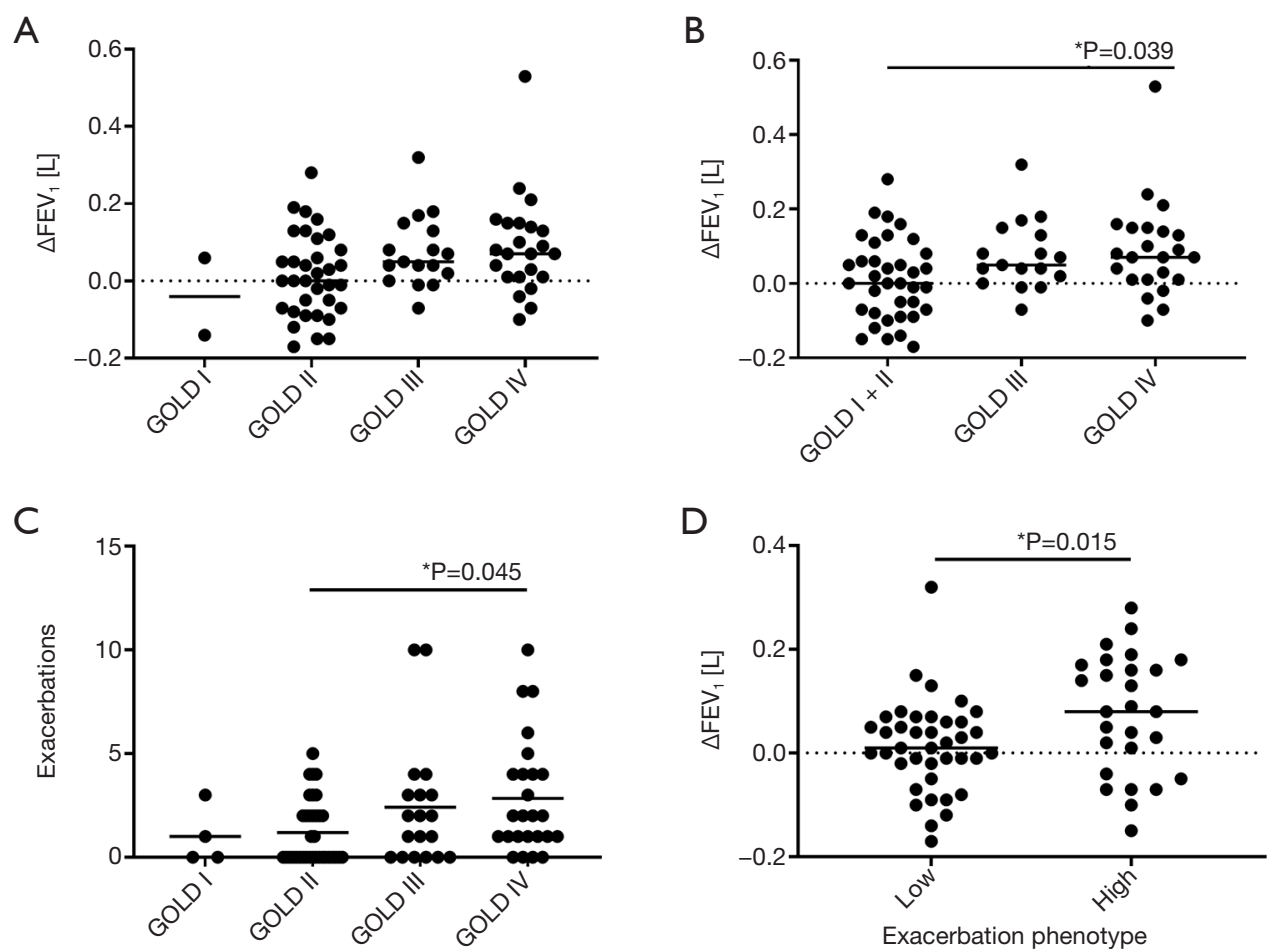

Figure 1 Progression of chronic obstructive pulmonary disease (COPD) and exacerbations. Data were analyzed for differences in the mean annual decrease in the forced expiratory volume in 1 second $\left(\Delta \mathrm{FEV}_{1}\right)$ between Global Initiative for Chronic Obstructive Pulmonary Diseases (GOLD) stages I to IV (A) or GOLD stages I + II to IV (B) and for differences in the number of exacerbations over the last 12 months between GOLD stages I to IV (C). Analyses were performed by Kruskal-Wallis and Dunn's multiple comparisons tests. Disease progression $\left(\triangle \mathrm{FEV}_{1}\right)$ was compared between patients of the low and high exacerbation phenotype by two-tailed Mann-Whitney test (D). The median/ group is indicated. * $\mathrm{P}<0.05$.

in GOLD stage IV on average suffered from 25-OHD deficiency. The frequency of patients yielding serum 25OHD levels below $20 \mathrm{ng} / \mathrm{mL}$ increased with the GOLD stage (GOLD I none, GOLD II 43\%, GOLD III 59\%, GOLD IV 75\%) (Figure 2D). Overall, these data indicated that COPD patients were likely to suffer from insufficient or deficient serum 25-OHD levels and low 25-OHD levels were significantly correlated with COPD severity.

\section{Association between serum 25-OHD levels and systemic inflammatory parameters}

Regarding systemic inflammatory parameters, there was no correlation between serum 25-OHD levels and TNF- $\alpha$ (Figure $3 A$ ). However, we observed fair negative correlation for the CRP (Spearman $\mathrm{r}=-0.32, \mathrm{P}<0.01$ ) (Figure $3 B$ ) as well as a weak negative correlation for IL-6 (Spearman $\mathrm{r}=-0.23$, $\mathrm{P}=0.028$ ) (Figure 3C). These data indicate decreased serum
25-OHD levels to be associated with an increase in systemic inflammation in COPD patients.

\section{Association of serum 25-OHD levels and sunlight exposure} with the frequency of exacerbations and disease progression

We did not observe a significant correlation between serum 25-OHD levels and the frequency of exacerbations (Figure S1) or significant changes in 25-OHD levels between patients of the different exacerbation phenotypes (Mann-Whitney test, $\mathrm{P}=0.399$ ) (Figure 4A). However, regarding disease progression we observed weak negative correlation of serum 25-OHD levels and $\triangle \mathrm{FEV}_{1}$ (Spearman $\mathrm{r}=-0.26, \mathrm{P}=0.024$ ), indicating an association between low serum vitamin $\mathrm{D}$ levels and relatively rapid previous disease progression (Figure 4B).

As could be expected, there was fair positive correlation between 25-OHD levels and the reported average hours 
A

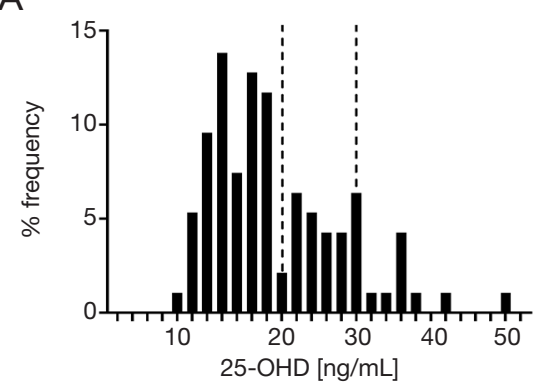

C

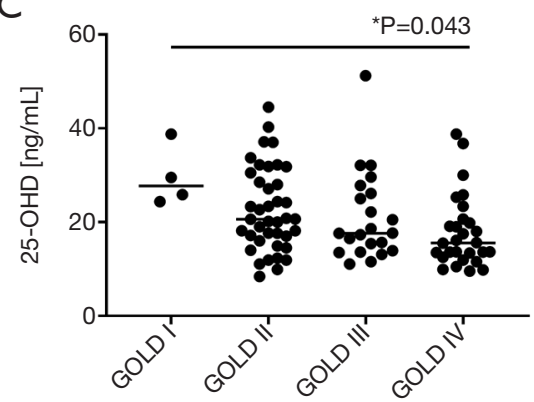

B

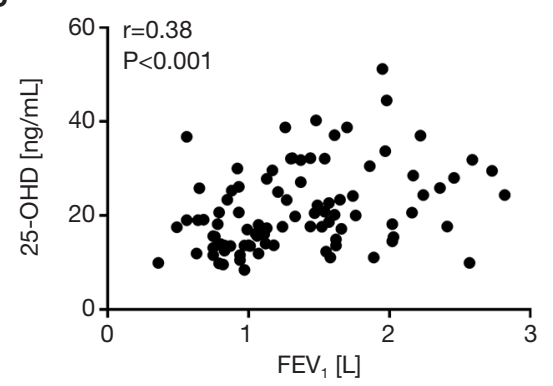

D

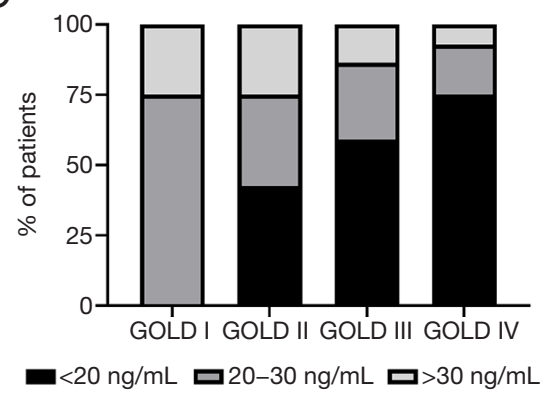

Figure 2 Correlations between serum 25-hydroxyvitamin D (25-OHD) levels and disease severity. Data were analyzed for the relative distribution of serum 25-OHD levels in the cohort of patients with chronic obstructive pulmonary disease (COPD) (A) and for correlations between serum 25-OHD levels and the forced expiratory volume in 1 second $\left(\mathrm{FEV}_{1}\right)(\mathrm{B})$. The Spearman $\mathrm{r}$ and the respective $\mathrm{P}$ value are indicated. Global Initiative for Chronic Obstructive Pulmonary Diseases (GOLD) stage dependent differences in serum 25-OHD levels were analyzed by Kruskal-Wallis and Dunn's multiple comparison tests (C). The median/group is indicated. The frequency of serum $25-$ OHD levels below $20 \mathrm{ng} / \mathrm{mL}$, between $20 \mathrm{ng} / \mathrm{mL}$ and $30 \mathrm{ng} / \mathrm{mL}$ as well as above $30 \mathrm{ng} / \mathrm{mL}$ in the different GOLD stages was assessed (D). *, $\mathrm{P}<0.05$.

of weekly sunlight exposure (Spearman $\mathrm{r}=0.35, \mathrm{P}<0.001$ ) (Figure S2A) as well as average frequency of sunlight exposures per week (Spearman $\mathrm{r}=0.33, \mathrm{P}=0.001$ ) (Figure $\mathrm{S} 2 \mathrm{~B}$ ). As for 25-OHD levels (Figure 2C), the mean reported average hours of weekly sunlight exposure were lowest in patients of GOLD stage IV [GOLD I 18 (SD 0); GOLD II 10.8 (SD 6.3); GOLD III 11.9 (SD 5.3); GOLD IV 9.2 (SD 6.9)] but there was no significant association between the GOLD stage and the reported average hours of weekly sunlight exposure (Kruskal-Wallis test, $\mathrm{P}=0.051$ ) (Figure $4 C)$. Nevertheless, there was weak negative correlation between the reported average hours of weekly sunlight exposure and disease progression expressed as $\triangle \mathrm{FEV} \mathrm{V}_{1}$ (Spearman $r=-0.25, \mathrm{P}=0.03$; Figure S3). Furthermore, patients of the high-frequency exacerbation phenotype reported significantly less average hours of weekly sunlight exposure than those of the low-frequency exacerbation phenotype (Mann-Whitney test, $\mathrm{P}=0.0013$ ) (Figure 4D), indicating a negative association between sunlight exposure and the exacerbation frequency, which was not observed for 25-OHD levels and the exacerbation frequency (Figure 4A). There were no significant correlations between 25-OHD levels and body weight, BMI or smoking (Figure S4).

\section{Multi-variable regression analysis of associations between 25-OHD and COPD parameters}

Multi-variable linear regression analysis was performed to test which of the correlated factors GOLD stage, $\mathrm{FEV}_{1}$, $\triangle \mathrm{FEV}_{1}$, CRP, IL-6, average hours of weekly sunlight exposure and frequency of sunlight exposures per week in combination affected the serum 25-OHD level. As a result, the three independent variables $\mathrm{FEV}_{1}, \mathrm{CRP}$ and the reported frequency of sun exposure per week showed a significant influence on the dependent variable serum 25OHD level (Table 4). These three independent variables 
A
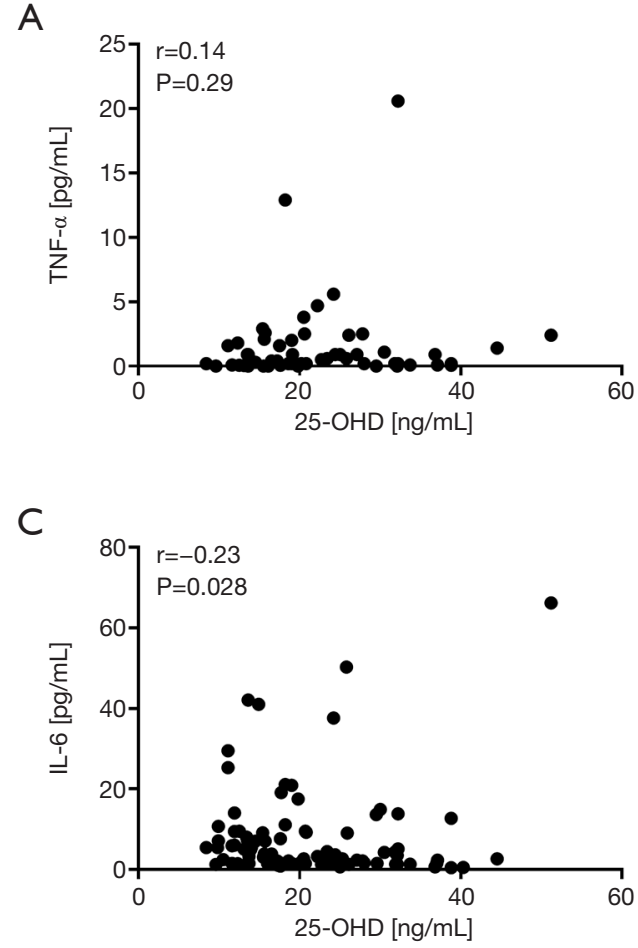

B

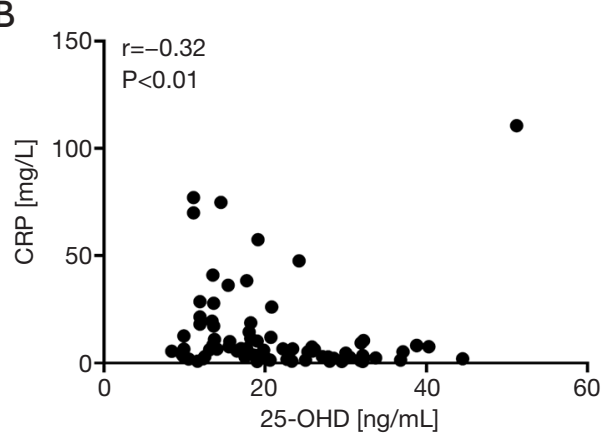

Figure 3 Correlations between serum 25-hydroxyvitamin D (25-OHD) levels and inflammatory parameters. Data were analyzed for correlations between serum 25-OHD levels and serum tumor necrosis factor (TNF)- $\alpha$ (A), C-reactive protein (CRP) (B) and interleukin (IL)-6 (C). The Spearman $\mathrm{r}$ and the respective $\mathrm{P}$ value are indicated.

explained $26.7 \%$ of the total variance in the dependent variable (adjusted $\mathrm{R}$ squared $=0.267$ ).

\section{Discussion}

In our study, we report associations between serum 25-OHD levels and disease severity in COPD. Our data furthermore suggest associations between serum 25-OHD and prior disease progression and systemic inflammation, but not the frequency of exacerbations. We addressed correlations between disease severity, disease progression, exacerbation frequency as well as the inflammatory status and 25-OHD levels in a cohort of 94 COPD patients. Most frequent comorbidities in these COPD patients were excluded and the classification of disease severity was performed according to the functional GOLD stages, an objective disease-related approach that however rather neglects comorbidities. Nevertheless, and despite possible interference by comorbidities, we observed a number of significant associations between serum 25-OHD levels and different parameters of COPD.

In our cohort, there were mainly patients in GOLD stage II to IV as patients in GOLD stage I are rarely treated by specialized pneumonologists. Disease progression as well as the frequency of exacerbations significantly differed between GOLD stages and patients in GOLD stage IV exhibited the highest median 3-year decline in $\mathrm{FEV}_{1}$. In contrast to our results, a large COPD study reported that patients with the largest rate of decline in lung function suffered from less severe lung disease at baseline $(26,27)$. In our cohort, patients in GOLD stage IV furthermore showed the highest median number of exacerbations. In line with reports from other COPD studies (28), frequently exacerbating patients had experienced a significantly increased decline in lung function, supporting the understanding that exacerbations are key events in COPD with a high relevance for the disease (29).

In our cohort, most patients indeed yielded suboptimal 25-OHD levels, more than half revealed insufficient levels and we observed a significant correlation of serum 25OHD levels and the $\mathrm{FEV}_{1}$. Furthermore, in GOLD stage 
A

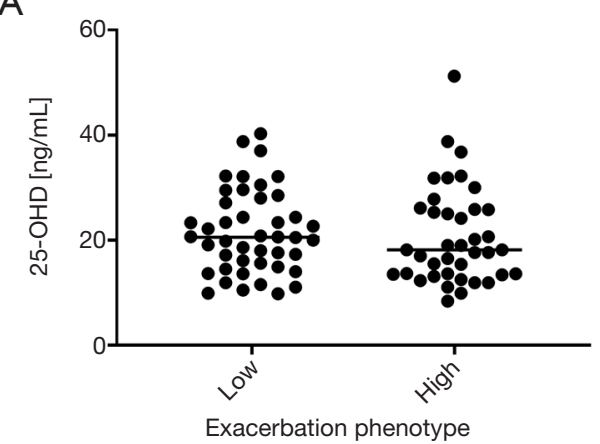

C

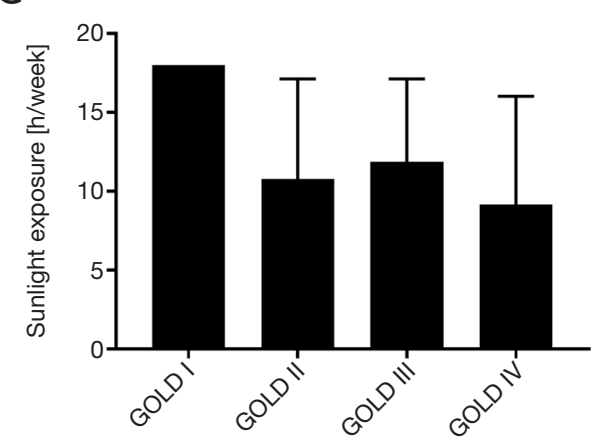

B

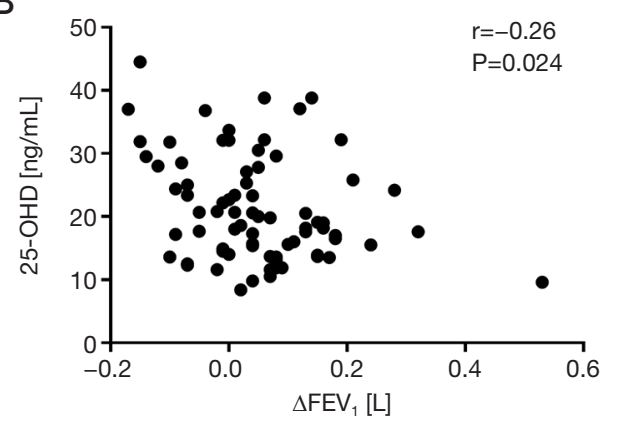

D

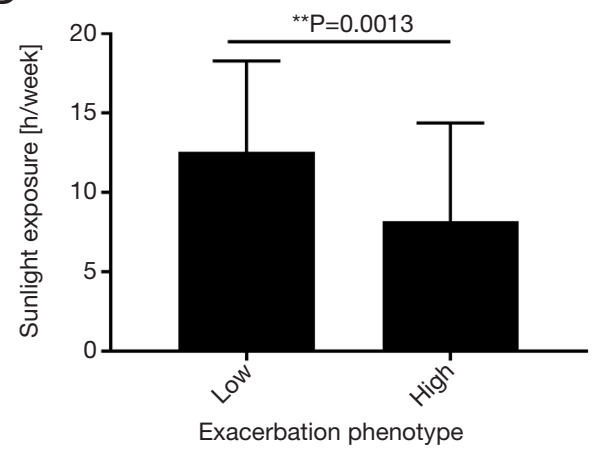

Figure 4 Correlations between serum 25-hydroxyvitamin D (25-OHD) levels as well as sunlight exposure to disease progression and exacerbations. Exacerbation phenotype dependent differences in serum 25-OHD levels were analyzed by two-tailed Mann-Whitney test (A) (not significant, $\mathrm{P}=0.66$ ). The median/group is indicated. Data were analyzed for correlations between serum 25-OHD levels and disease progression (mean annual decrease in the forced expiratory volume in 1 second, $\triangle \mathrm{FEV}_{1}$ ) and the Spearman $\mathrm{r}$ and the respective $\mathrm{P}$ value are indicated (B). Data were analyzed for Global Initiative for Chronic Obstructive Pulmonary Diseases (GOLD) stage dependent differences in sunlight exposure by Kruskal-Wallis and Dunns multiple comparisons tests (C) and for exacerbation phenotype dependent differences in sunlight exposure by two-tailed Mann-Whitney test $(\mathrm{P}=0.0013)(\mathrm{D})$. In $(\mathrm{C})$ and $(\mathrm{D})$ data are shown as mean with standard deviation. **, $\mathrm{P}<0.01$.

Table 4 Multi-variable regression analysis

\begin{tabular}{lccccc}
\hline Variable & $\begin{array}{c}\text { Un-standardized } \\
\text { regression coefficient B }\end{array}$ & Standard error & $\begin{array}{c}\text { Standardized } \\
\text { coefficient Beta }\end{array}$ & $\begin{array}{c}\text { Significance } \\
\text { (P value) }\end{array}$ & 95\% confidence interval \\
\hline FEV $_{1}$ & 4.914 & 1.948 & 0.303 & 0.014 & 1.013 \\
CRP & -0.217 & 0.074 & -0.326 & 0.005 & -0.365 \\
Sunlight exposure & 1.184 & 0.53 & 0.268 & 0.029 & 0.124 \\
(frequency per week) & & & & & 2.245 \\
\hline
\end{tabular}

Results of multi-variable regression analysis using backward selection on the variables Global Initiative for Chronic Obstructive Pulmonary Diseases (GOLD) stage, forced expiratory volume in 1 second $\left(\mathrm{FEV}_{1}\right)$, mean annual decrease in $\mathrm{FEV}_{1}$ over the previous three years, C-reactive protein (CRP), interleukin-6, the reported average hours of weekly sunlight exposure and the reported frequency of sunlight exposures per week. 
IV there was a mean 25 -OHD level below $20 \mathrm{ng} / \mathrm{mL}$, pointing at vitamin $\mathrm{D}$ deficiency. Taken together, our observations suggest a clear association between low 25-OHD levels and the current disease severity in the analyzed cohort of COPD patients and are in line with previous reports describing decreased 25-OHD levels in COPD patients that correlate with airflow limitation in lung function (7,30-32).

Generally, the associations between decreased serum 25OHD levels and COPD severity are relatively clear and well described. Nevertheless, limited and at times conflicting data exist on correlations between the vitamin D status and lung function decline $(33,34)$. A recent report however showed associations between vitamin $\mathrm{D}$ deficiency and both crosssectional as well as longitudinal lung function decline over 1 year (8). In contrast to assessing the predictive value of baseline 25-OHD levels with regard to disease progression, in our study we retrospectively addressed associations between current 25-OHD levels and prior lung function decline. As described above, in our cohort $\triangle \mathrm{FEV}_{1}$ was highest in the advanced stages of disease and there was a negative correlation with serum 25-OHD levels. These data point at an association between current 25-OHD levels and prior disease progression. Clearly, the question whether low 25OHD levels in COPD are cause or consequence remains (35). Therefore, also in light of the recent finding that the vitamin $\mathrm{D}$ metabolism is altered in COPD patients (36), in the future larger longitudinal studies will ideally further clarify not only the predictive value of baseline serum 25OHD levels in COPD patients but also how current 25OHD levels relate to prior lung function loss. This will be important in identifying mechanisms on how vitamin $\mathrm{D}$ acts on COPD disease progression and whether this displays a direct interaction.

The frequency of exacerbations is an important factor in COPD severity that strongly affects patients $(29,37,38)$. Clinically, associations between vitamin D deficiencies and respiratory infections have been proposed for the general population as well as in COPD $(7,9,12,39)$. We did not observe an association between 25-OHD levels and the exacerbation frequency in our cohort. Importantly, this is in line with several previously published studies that also did not observe significant associations between 25-OHD levels and exacerbations $(10,40-42)$. Therefore, the role of vitamin $\mathrm{D}$ in COPD exacerbations remains controversial and data on such associations, ideally also on a patient-specific level, will be essential when attempting to develop and investigate pathophysiological mechanisms of vitamin D deficiency in
COPD especially with regard to exacerbations.

In COPD patients, there is an individual systemic inflammatory component to the disease in addition to the local bronchial inflammation $(43,44)$. Generally, COPD may be associated with elevated inflammatory parameters like serum CRP, IL-6 and TNF- $\alpha$ (45). Accordingly in our study, COPD patients showed heterogeneous levels of inflammatory parameters and there was no correlation between the analyzed parameters for inflammation and disease severity and disease progression, while at the same time serum IL-6 was significantly elevated in patients of the high exacerbation phenotype. Furthermore, in those patients that were recruited as inpatients, significantly elevated levels of CRP and IL-6 were detected. Generally, our data support the theory that different heterogeneous inflammatory phenotypes exist in COPD $(43,46)$. Despite the lack of a correlation between inflammatory parameters and disease severity, we observed fair negative correlation for the CRP and weak negative correlation for IL-6 with serum 25-OHD levels. This is well in line with a very recent report describing correlations between a low 25-OHD status and inflammation in COPD patients (47). Altogether, these observations point at a possible interconnection between exacerbations, systemic inflammation and 25-OHD levels, which could be mediated by the immunomodulatory effect of vitamin $\mathrm{D}$ and the general risk of respiratory infections under vitamin D deficiency $(48,49)$.

Next to dietary uptake, serum 25-OHD levels mainly depend on sunlight exposure (23). Differences in lifestyle, physical exercise and thereby also sunlight exposure presumably display key factors in the associations between 25-OHD levels and disease severity in COPD. As generally listlessness increases with pronounced pulmonary impairment, it is assumed that also light exposure decreases with disease progression, which in turn predisposes for vitamin $\mathrm{D}$ deficiency $(7,19,50)$. In line with this, while the GOLD stage and weekly hours of sunlight exposure were not generally associated (Kruskal-Wallis test, $\mathrm{P}=0.051$ ), patients in GOLD stage IV reported significantly lower weekly hours of sunlight exposure than those in GOLD stage $\mathrm{I}$ in direct comparison (Mann-Whitney test, $\mathrm{P}=0.022$ ). At the same time, also mean 25-OHD levels significantly differed between GOLD stages (Kruskal-Wallis test, $\mathrm{P}=0.013$ ) with the lowest levels in GOLD stage IV. Multivariable regression analysis revealed a functional $\left(\mathrm{FEV}_{1}\right)$ as well as an inflammatory disease parameter (CRP) in combination with the frequency of sunlight exposure to significantly affect the level of 25-OHD. 
There are several limitations to our study. Disease severity was staged based on airflow limitation according to the GOLD classification. Since COPD assessment test (CAT) or Medical Research Council (MRC) dyspnea score data were not available for all patients, there was no ABCD classification. Due to the relatively small overall sample size, there is only a little number of patients in GOLD stages I and II causing potential bias. Therefore, for some analyses these two groups were combined or GOLD I was excluded from the analysis. In the light of the study size, it needs to be emphasized that $r$-values $<0.3$ indicate only very weak correlations that will need to be confirmed in larger cohorts. Sample collection occurred throughout the year and there was no consideration of the season. We analyzed a cohort of inpatients and outpatients which potentially display different disease status and comorbidities next to those excluding patients from the study were not further analyzed.

Ultimately, it will be a major challenge for future research to clearly discriminate between the baseline vitamin $\mathrm{D}$ status and its effects on the future course of the disease, including exacerbations, and COPD-mediated effects on 25-OHD levels, which in turn will then affect the disease. The question of vitamin $\mathrm{D}$ supplementation in COPD remains and several studies have indeed suggested a high potential to interfere with disease progression (51-53). Nevertheless, conflicting results have been obtained, up to now there is no explicit benefit for vitamin D supplementation in COPD and there are also caveats in vitamin D supplementation (19,54). Therefore, clearly larger longitudinal studies addressing the potential benefit of vitamin D substitution for the disease process in COPD are also needed, ideally at the same time addressing the underlying pathophysiological mechanisms.

\section{Conclusions}

In line with published data, we observed reduced levels of serum 25-OHD that significantly correlated with disease severity in COPD patients. Furthermore, we describe a significant negative correlation between serum 25-OHD levels and prior lung function loss. At the same time, there was no correlation of serum 25-OHD levels with the frequency of experienced exacerbations. Therefore, insufficient 25-OHD levels possibly affect lung function independently of exacerbations and future studies will be needed to address the underlying mechanisms and to allow targeted intervention, for example by vitamin $\mathrm{D}$ supplementation.

\section{Acknowledgments}

Funding: None.

\section{Footnote}

Reporting Checklist: The authors have completed the STROBE reporting checklist. Available at http://dx.doi. org/10.21037/jtd-20-3221

Data Sharing Statement: Available at http://dx.doi. org/10.21037/jtd-20-3221

Conflicts of Interest: All authors have completed the ICMJE uniform disclosure form (available at http://dx.doi. org/10.21037/jtd-20-3221). All authors have no conflicts of interest to declare.

Ethical Statement: The authors are accountable for all aspects of the work in ensuring that questions related to the accuracy or integrity of any part of the work are appropriately investigated and resolved. The study was conducted in accordance with the Declaration of Helsinki (as revised in 2013) and approved by the institutional ethical committee (Ethikkommission of the Otto-von-Guericke University Magdeburg; file no. 12/11). All patients gave written informed consent.

Open Access Statement: This is an Open Access article distributed in accordance with the Creative Commons Attribution-NonCommercial-NoDerivs 4.0 International License (CC BY-NC-ND 4.0), which permits the noncommercial replication and distribution of the article with the strict proviso that no changes or edits are made and the original work is properly cited (including links to both the formal publication through the relevant DOI and the license). See: https://creativecommons.org/licenses/by-nc-nd/4.0/.

\section{References}

1. Lopez AD, Shibuya K, Rao C, et al. Chronic obstructive pulmonary disease: current burden and future projections. Eur Respir J 2006;27:397-412.

2. Lopez AD, Murray CC. The global burden of disease, 1990-2020. Nat Med 1998;4:1241-3.

3. Global Initiative for Asthma. 2021 GINA Report, Global Strategy for Asthma Management and Prevention. Available online: https://ginasthma.org/ 
gina-reports/

4. Battaglia S, Basile M, Scichilone N, et al. Prevalence of Co-morbidities and Severity of COPD. COPD 2015;12:390-4.

5. Vanfleteren LE, Spruit MA, Groenen M, et al. Clusters of comorbidities based on validated objective measurements and systemic inflammation in patients with chronic obstructive pulmonary disease. Am J Respir Crit Care Med 2013;187:728-35.

6. Sandhu MS, Casale TB. The role of vitamin D in asthma. Ann Allergy Asthma Im-munol 2010;105:191-9; quiz 200-2, 217.

7. Kokturk N, Baha A, Oh YM, et al. Vitamin D deficiency: What does it mean for chronic obstructive pulmonary disease (COPD)? a compherensive review for pulmonologists. Clin Respir J 2018;12:382-97.

8. Burkes RM, Ceppe AS, Doerschuk CM, et al. Associations Among 25-Hydroxyvitamin D Levels, Lung Function, and Exacerbation Outcomes in COPD: An Analysis of the SPIROMICS Cohort. Chest 2020;157:856-65.

9. Ginde AA, Mansbach JM, Camargo CA Jr. Association between serum 25-hydroxyvitamin D level and upper respiratory tract infection in the Third National Health and Nutrition Examination Survey. Arch Intern Med 2009;169:384-90.

10. Kunisaki KM, Niewoehner DE, Connett JE, et al. Vitamin D levels and risk of acute exacerbations of chronic obstructive pulmonary disease: a prospective cohort study. Am J Respir Crit Care Med 2012;185:286-90.

11. Malinovschi A, Masoero M, Bellocchia M, et al. Severe vitamin $\mathrm{D}$ deficiency is as-sociated with frequent exacerbations and hospitalization in COPD patients. Respir Res 2014;15:131.

12. Abioye AI, Bromage S, Fawzi W. Effect of micronutrient supplements on influenza and other respiratory tract infections among adults: a systematic review and me-taanalysis. BMJ Glob Health 2021;6:e003176.

13. Zhu M, Wang T, Wang C, et al. The association between vitamin D and COPD risk, severity, and exacerbation: an updated systematic review and meta-analysis. Int J Chron Obstruct Pulmon Dis 2016;11:2597-607.

14. Hornikx M, Van Remoortel H, Lehouck A, et al. Vitamin $\mathrm{D}$ supplementation during rehabilitation in COPD: a secondary analysis of a randomized trial. Respir Res 2012;13:84.

15. Tsiligianni IG, van der Molen T. A systematic review of the role of vitamin insuffi-ciencies and supplementation in COPD. Respir Res 2010;11:171.
16. Li X, He J, Yu M, et al. The efficacy of vitamin D therapy for patients with COPD: a meta-analysis of randomized controlled trials. Ann Palliat Med 2020;9:286-97.

17. Chen FY, Xiao M, Ling B, et al. Vitamin D does not improve lung function decline in COPD: a meta-analysis. Eur Rev Med Pharmacol Sci 2019;23:8637-44.

18. Jolliffe DA, Greenberg L, Hooper RL, et al. Vitamin D to prevent exacerbations of COPD: systematic review and meta-analysis of individual participant data from randomised controlled trials. Thorax 2019;74:337-45.

19. Janssens W, Decramer M, Mathieu C, et al. Vitamin D and chronic obstructive pul-monary disease: hype or reality? Lancet Respir Med 2013;1:804-12.

20. Fabbri L, Pauwels RA, Hurd SS, et al. Global Strategy for the Diagnosis, Management, and Prevention of Chronic Obstructive Pulmonary Disease: GOLD Executive Summary updated 2003. COPD 2004;1:105-41; discussion 103-4.

21. Burge S, Wedzicha JA. COPD exacerbations: definitions and classifications. Eur Respir J Suppl 2003;41:46s-53s.

22. Holick MF. The vitamin D deficiency pandemic: Approaches for diagnosis, treatment and prevention. Rev Endocr Metab Disord 2017;18:153-65.

23. Holick MF, Binkley NC, Bischoff-Ferrari HA, et al. Evaluation, treatment, and pre-vention of vitamin D deficiency: an Endocrine Society clinical practice guideline. J Clin Endocrinol Metab 2011;96:1911-30.

24. Thomas L. Clinical Laboratory Diagnostics 2020. 2020.

25. Motulsky HJ. GraphPad Statistics Guide. Available online: https://www.graphpad.com/guides/prism/latest/ statistics/index.htm accessed September 2020.

26. Kesten S, Celli B, Decramer M, et al. Adverse health consequences in COPD patients with rapid decline in FEV1-evidence from the UPLIFT trial. Respir Res 2011;12:129.

27. Tashkin DP, Celli B, Senn S, et al. A 4-year trial of tiotropium in chronic obstructive pulmonary disease. $\mathrm{N}$ Engl J Med 2008;359:1543-54.

28. Wedzicha JA, Brill SE, Allinson JP, et al. Mechanisms and impact of the frequent exacerbator phenotype in chronic obstructive pulmonary disease. BMC Med 2013;11:181.

29. Hoogendoorn M, Feenstra TL, Hoogenveen RT, et al. Association between lung function and exacerbation frequency in patients with COPD. Int J Chron Obstruct Pulmon Dis 2010;5:435-44.

30. Berg I, Hanson C, Sayles H, et al. Vitamin D, vitamin D binding protein, lung function and structure in COPD. Respir Med 2013;107:1578-88.

31. Black PN, Scragg R. Relationship between serum 25-hydroxyvitamin $\mathrm{d}$ and pulmo-nary function in the third 
national health and nutrition examination survey. Chest 2005;128:3792-8.

32. Janssens W, Bouillon R, Claes B, et al. Vitamin D deficiency is highly prevalent in COPD and correlates with variants in the vitamin D-binding gene. Thorax 2010;65:215-20.

33. Afzal S, Lange P, Bojesen SE, et al. Plasma 25-hydroxyvitamin D, lung function and risk of chronic obstructive pulmonary disease. Thorax 2014;69:24-31.

34. Persson LJ, Aanerud M, Hiemstra PS, et al. Vitamin D, vitamin $\mathrm{D}$ binding protein, and longitudinal outcomes in COPD. PLoS One 2015;10:e0121622.

35. Hiemstra PS, de Jongh RT. Vitamin D Deficiency in Asthma and Chronic Obstructive Pulmonary Disease. A Chicken-or-Egg Story. Am J Respir Crit Care Med 2020;202:312-3.

36. Jolliffe DA, Stefanidis C, Wang Z, et al. Vitamin D Metabolism Is Dysregulated in Asthma and Chronic Obstructive Pulmonary Disease. Am J Respir Crit Care Med 2020;202:371-82.

37. Agusti A, Edwards LD, Celli B, et al. Characteristics, stability and outcomes of the 2011 GOLD COPD groups in the ECLIPSE cohort. Eur Respir J 2013;42:636-46.

38. Hurst JR, Vestbo J, Anzueto A, et al. Susceptibility to exacerbation in chronic ob-structive pulmonary disease. $\mathrm{N}$ Engl J Med 2010;363:1128-38.

39. Laaksi I, Ruohola JP, Tuohimaa P, et al. An association of serum vitamin $\mathrm{D}$ concen-trations $<40 \mathrm{nmol} / \mathrm{L}$ with acute respiratory tract infection in young Finnish men. Am J Clin Nutr 2007;86:714-7.

40. Mekov E, Slavova Y, Tsakova A, et al. Vitamin D Deficiency and Insufficiency in Hospitalized COPD Patients. PLoS One 2015;10:e129080.

41. Puhan MA, Siebeling L, Frei A, et al. No association of 25-hydroxyvitamin $\mathrm{D}$ with exacerbations in primary care patients with COPD. Chest 2014;145:37-43.

42. Quint JK, Donaldson GC, Wassef N, et al. 25-hydroxyvitamin D deficiency, exacer-bation frequency and human rhinovirus exacerbations in chronic obstructive pulmo-nary disease. BMC Pulm Med 2012;12:28.

43. Barnes PJ. Inflammatory mechanisms in patients with chronic obstructive pulmonary disease. J Allergy Clin Immunol 2016;138:16-27.

44. Kleniewska A, Walusiak-Skorupa J, Piotrowski W, et al. Comparison of biomarkers in serum and induced sputum of patients with occupational asthma and chronic ob-structive pulmonary disease. J Occup Health 2016;58:333-9.
45. Agustí A, Edwards LD, Rennard SI, et al. Persistent systemic inflammation is asso-ciated with poor clinical outcomes in COPD: a novel phenotype. PLoS One 2012;7:e37483.

46. Zhou A, Zhou Z, Zhao Y, et al. The recent advances of phenotypes in acute exacer-bations of COPD. Int J Chron Obstruct Pulmon Dis 2017;12:1009-18.

47. Fu L, Fei J, Tan ZX, et al. Low Vitamin D Status Is Associated with Inflammation in Patients with Chronic Obstructive Pulmonary Disease. J Immunol 2021;206:515-23.

48. Banerjee A, Panettieri R Jr. Vitamin D modulates airway smooth muscle function in COPD. Curr Opin Pharmacol 2012;12:266-74.

49. Hansdottir S, Monick MM. Vitamin D effects on lung immunity and respiratory dis-eases. Vitam Horm 2011;86:217-37.

50. Kentson M, Leanderson P, Jacobson P, et al. The influence of disease severity and lifestyle factors on the peak annual 25(OH)D value of COPD patients. Int J Chron Obstruct Pulmon Dis 2018;13:1389-98.

51. Jolliffe DA, Greenberg L, Hooper RL, et al. Vitamin $\mathrm{D}$ supplementation to prevent asthma exacerbations: a systematic review and meta-analysis of individual participant data. Lancet Respir Med 2017;5:881-90.

52. Maes K, Serre J, Mathyssen C, et al. Targeting Vitamin D Deficiency to Limit Exac-erbations in Respiratory Diseases: Utopia or Strategy with Potential? Calcif Tissue Int 2020;106:76-87.

53. Martineau AR, James WY, Hooper RL, et al. Vitamin D3 supplementation in patients with chronic obstructive pulmonary disease (ViDiCO): a multicentre, doubleblind, randomised controlled trial. Lancet Respir Med 2015;3:120-30.

54. Rafiq R, Prins HJ, Boersma WG, et al. Effects of daily vitamin $\mathrm{D}$ supplementation on respiratory muscle strength and physical performance in vitamin D-deficient COPD patients: a pilot trial. Int J Chron Obstruct Pulmon Dis 2017;12:2583-92.

Cite this article as: Jorde I, Stegemann-Koniszewski S, Papra K, Föllner S, Lux A, Schreiber J, Lücke E. Association of serum vitamin D levels with disease severity, systemic inflammation, prior lung function loss and exacerbations in a cohort of patients with chronic obstructive pulmonary disease (COPD). J Thorac Dis 2021;13(6):3597-3609. doi: 10.21037/jtd-20-3221 


\section{Supplementary}

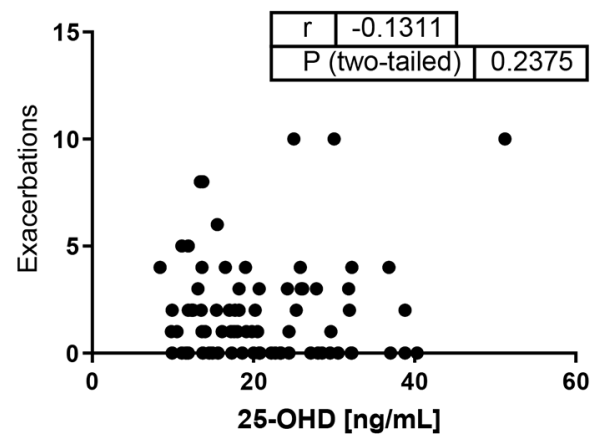

Figure S1 Spearman correlation between the number of exacerbations and 25-hydroxyvitamin D (25-OHD levels).

A

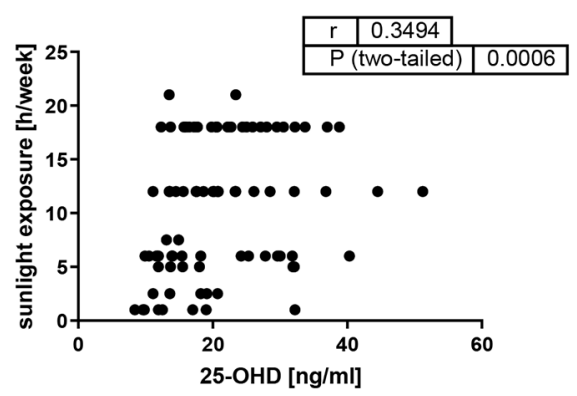

B

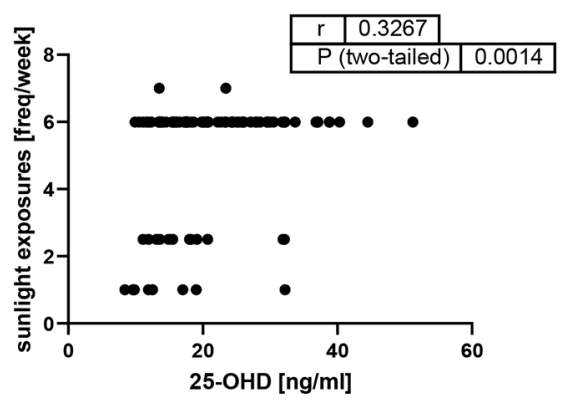

Figure S2 Spearman correlation between the reported average weekly hours of sunlight exposure (A) as well as the reported frequency of sunlight exposures/week (B) and 25-hydroxyvitamin D (25-OHD) levels.

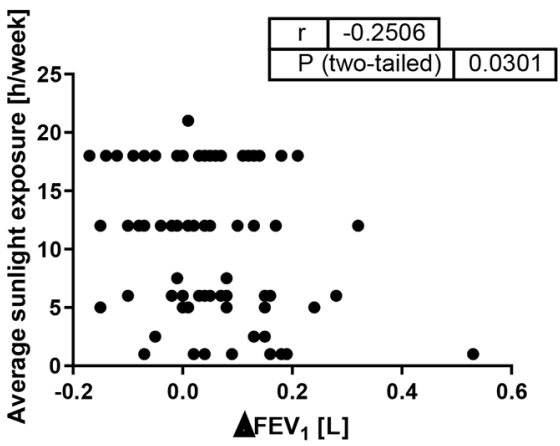

Figure S3 Spearman correlation between the average hours of weekly sunlight exposure and disease progression as in $\mathrm{FEV}_{1}$ decline. $\mathrm{FEV}_{1}$, forced expiratory volume in 1 second. 
A

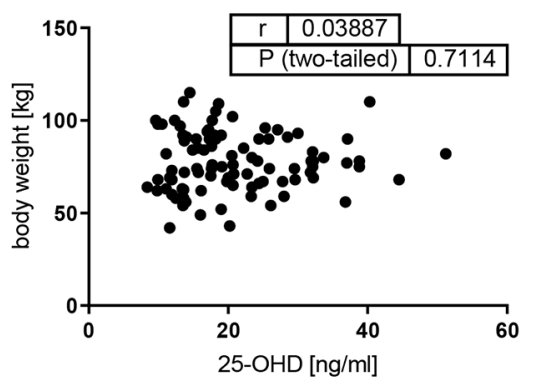

C

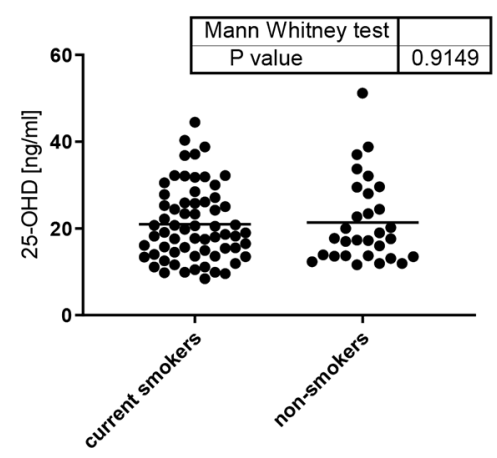

B

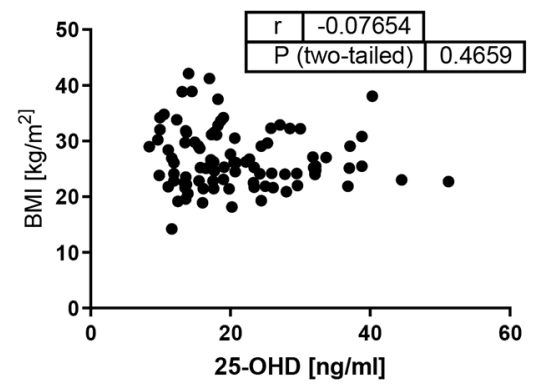

Figure S4 Spearman correlation analysis for body weight and 25-hydroxyvitamin D (25-OHD levels) (A), Spearman correlation analysis for body mass index (BMI) and 25-OHD levels (B), and comparison of 25-OHD levels between current smokers and non-smokers (MannWhitney test) (C). 